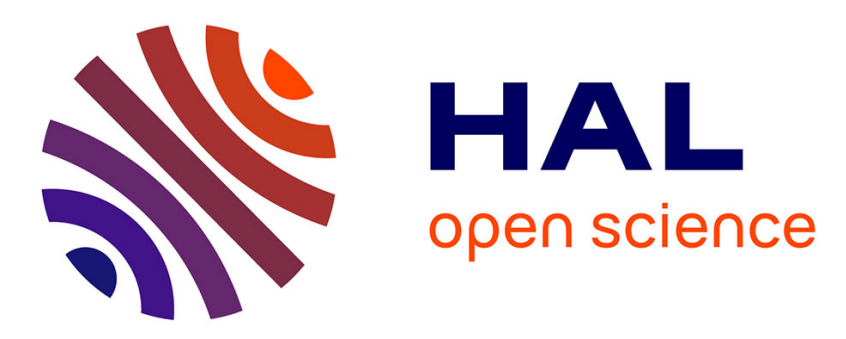

\title{
Verbal emotional memory in children and adolescents with temporal lobe epilepsy: A first study
}

Isabelle Jambaqué, Charlotte Pinabiaux, Célia Dubouch, Martine Fohlen, Christine Bulteau, Olivier Delalande

\section{- To cite this version:}

Isabelle Jambaqué, Charlotte Pinabiaux, Célia Dubouch, Martine Fohlen, Christine Bulteau, et al.. Verbal emotional memory in children and adolescents with temporal lobe epilepsy: A first study. Epilepsy \& Behavior, 2009, 16 (1), pp.69 - 75. 10.1016/j.yebeh.2009.07.006 . hal-01392532

\section{HAL Id: hal-01392532 \\ https://hal.science/hal-01392532}

Submitted on 3 Feb 2021

HAL is a multi-disciplinary open access archive for the deposit and dissemination of scientific research documents, whether they are published or not. The documents may come from teaching and research institutions in France or abroad, or from public or private research centers.
L'archive ouverte pluridisciplinaire HAL, est destinée au dépôt et à la diffusion de documents scientifiques de niveau recherche, publiés ou non, émanant des établissements d'enseignement et de recherche français ou étrangers, des laboratoires publics ou privés. 


\title{
Verbal emotional memory in children and adolescents with temporal lobe epilepsy: A first study
}

\author{
Isabelle Jambaqué a,b,*, Charlotte Pinabiaux ${ }^{\mathrm{a}, \mathrm{b}, \mathrm{c}}$, Célia Dubouch ${ }^{\mathrm{a}, \mathrm{d}}$, Martine Fohlen ${ }^{\mathrm{b}}$, Christine Bulteau ${ }^{\mathrm{a}, \mathrm{b}}$, \\ Olivier Delalande ${ }^{\mathrm{b}}$ \\ a Laboratoire de Psychologie et Neurosciences Cognitives (UMR CNRS 8189), Université Paris Descartes, Institut de Psychologie, Paris, France \\ ${ }^{\mathrm{b}}$ Fondation Rothschild, Unité de Neurochirurgie Pédiatrique, Paris, France \\ ' Inserm U663, Université Paris Descartes, Paris, France \\ ${ }^{\mathrm{d}}$ APHP, Hôpital Necker-Enfants Malades, Departement de Neuropédiatrie, Centre de référence épilepsies rares, Paris, France
}

ABSTRACT That emotional memory enhancement is compromised in adult patients with temporal lobe epilepsy (TLE), particularly in the case of early cerebral damage, has been suspected. We conducted a study in which we compared 20 children and adolescents aged 11-15 years with early TLE with 40 healthy control subjects. We studied the effect of emotional information on verbal memory performance using story recall and word list learning tasks. Our results highlighted the existence of emotional memory facilitation in healthy subjects, whereas there was no beneficial impact of emotional material on memory in young patients with TLE. Our study suggests that early TLE can impair the development of emotional memory processes.

Keywords: Temporal lobe epilepsy; Children; Adolescents; Memory; Emotion

\section{Introduction}

The impact of emotionally relevant stimuli on memory performance in healthy adults is well documented, highlighting the role of the amygdala in memory functioning [1-6]. Temporal lobe epilepsy (TLE) can disrupt memory function, can cause emotional disorders, and may be an interesting model in which to study the interaction between memory and emotion [7]. Studies aimed at determining the effects of TLE on emotional memory have yielded some controversial results. Phelps et al. [8] reported that adults who had undergone left or right temporal lobectomy had normal enhancement for emotional words (recall of a list) and enhanced recall for neutral words embedded in emotional sentences. Brierley et al. [9] found that performance of patients who had undergone left or right temporal lobectomy was comparable to that of matched controls on emotional story recall and word recognition tasks [10]. Nevertheless, the beneficial effect of emotion on verbal memory was less evident in the left temporal lobectomy group. Buchanan et al. [11] evaluated 14 patients with unilateral amygdala damage (13 of 14 after temporal lobectomy) using emotional

\footnotetext{
* Corresponding author. Address: Université Paris Descartes, Institut de Psychologie, Laboratoire Psychologie et Neurosciences Cognitives, CNRS UMR 8189, 71 avenue Edouard Vaillant 92774 Boulogne Billancourt Cedex, France. Fax: +33155 205985.

E-mail address: isabelle.jambaque@parisdescartes.fr (I. Jambaqué).
}

and neutral pictures accompanied by verbal narratives. Patients with right-sided damage showed the normal pattern of facilitation of memory by emotion. On the other hand, patients with left-sided damage showed more severe deficits in encoding emotional stories than affective pictures. Frank and Tomaz [12] also evidenced lateralized impairment of emotional enhancement using a story paradigm in patients with TLE. Neuroimaging studies provide further evidence that emotional memory is sustained by a mutual dependence between amygdala and hippocampus. Richardson et al. [13] used an fMRI event-related paradigm to compare emotional and neutral word encoding activations in 16 patients with left TLE and 12 healthy volunteers. When the left amydgala was damaged, a decrease in cerebral activity associated with a decrease in emotional word activity, with respect to neutral word activity, was observed in left hippocampus. In patients who had had a significant left hippocampus volumetric loss, a decrease in left amygdala activity and a functional compensatory shift toward the right amygdala were reported.

A loss of emotional enhancement of narrative material in patients with TLE with early, but not late, acquired amygdala damage has been reported [14]. However, there is no comprehensive study that has investigated the link between memory and emotion in children or adolescents with TLE. This issue is of importance given that memory may be impaired early by epilepsy and that memory deficits may be related to hemispheric specialization in childhood [15-17]. Recently, deficits in facial emotion recognition have also 
been reported in children and adolescents with TLE [18]. The latter results were positively correlated with age at epilepsy onset and occurrence of febrile convulsions in the first years of life.

The aim of the work described here was to study the emotional modulation of verbal memory in children and adolescents with early TLE. Memory performance of young patients with TLE aged 11-15 years was compared with that of healthy controls on two measures of verbal episodic memory. First, we employed a story paradigm, which constitutes an ecological measure where meaning and context help retrieval and allow combination of neutral and emotional elements in the same structure. Second, we investigated emotional memory enhancement on the basis of confrontation of verbal learning when using a neutral word list and an emotional word list. We hypothesized that the effect of emotional information should vary when comparing healthy children and adolescents with those with TLE on verbal memory tasks.

\section{Methods}

\subsection{Participants}

The study involved 20 children and adolescents with unilateral TLE (10 left TLE, 10 right TLE) and 40 healthy controls aged 11-15. All participants attended a regular school as an indicator of normal cognitive development. Patients had been referred for evaluation for epilepsy surgery at the Pediatric Neurosurgery Unit of the Fondation Rothschild (Paris, France). Inclusion criteria were diagnosis of TLE based on clinical history, seizure semiology, prolonged video/EEG monitoring, and MRI findings of hippocampal atrophy and/or temporal cortical lesions. Eight patients had undergone temporal resection and were seizure free at the time of neuropsychological evaluation. We included only right-handed patients with an IQ >70. Cognitive efficiency, as assessed by Full Scale IQ (IQ), Verbal IQ (VIQ), and Performance IQ (PIQ), did not differ between the clinical groups (IQ and PIQ: $F(1,18)$ values $<1$, ns; VIQ: $F(1,18)=2.77$, ns), and Digit Span measures were normative. Although we did not include patients with severe behavior disorders, a number of subjects obtained scores in the borderline or pathological clinical range on the Achenbach Child Behavior Checklist (CBCL), a widely used parent-report questionnaire for children with epilepsy [19]. Table 1 summarizes demographic information for all participants and the IQ age at seizure onset, type of lesion, and Digit Span and CBLC scores for the two patient groups.

\subsection{Memory testing}

\subsubsection{Story recall}

We employed a story recall paradigm taken from Signoret's memory battery [20]. A prose passage is read to the subject, and retention is assessed by having the subject retell the story (immediate and delayed story recall). The story is about "a man who dreams to buy a red car but when he believes to find the car of his dreams learns that it always "breaks down." This story contains not only factual, spatial, and temporal information (e.g., "car," "in the morning," "in a corner place"), but also elements that can be considered emotional. A jury of 10 adults and 10 adolescents indicated segments that would be considered neutral or emotional. Emotional target elements are either emotional items themselves (e.g., "dream," "sad") or are embedded in emotional sentence context (e.g., "The car is out of order"). Story recall was scored by counting the number of neutral (per 10) and emotional (per 10) units.

\subsubsection{Recall of word lists}

The test consists of learning and free recall of two lists of words (12 common words and 12 emotional words). The procedure was
Table 1

Demographics of the samples.

\begin{tabular}{llll}
\hline & Left TLE & Right TLE & Controls \\
\hline$N$ & $10^{\mathrm{a}}$ & $10^{\mathrm{a}}$ & $40^{\mathrm{a}}$ \\
Mean (SD) age (years) & $13(1.3)$ & $13.2(1.1)$ & $13(1.2)$ \\
Gender (male/female) & $4 / 6$ & $7 / 3$ & $20 / 20$ \\
Age at first seizure & $4.9(2.2)$ & $5.3(2.3)$ & $\mathrm{NA}^{\mathrm{b}}$ \\
Surgery (pre-/postoperative) & $6 / 4$ & $6 / 4$ & $\mathrm{NA}$ \\
Type of lesion & & & \\
Sclerosis, atrophy & 4 & 7 & $\mathrm{NA}$ \\
Dysplasia & 4 & 2 & $\mathrm{NA}$ \\
Tumor (ganglioma/DNET & & $\mathrm{NA}$ \\
Ischemic & $1 / 3$ & $0 / 2$ & $\mathrm{NA}$ \\
Full scale IQ (WISC) & 1 & - & $\mathrm{NA}$ \\
Verbal IQ & $92.8(15.02)$ & $97.2(15.13)$ & $\mathrm{NA}$ \\
Performance IQ & $89.7(17.69)$ & $102.5(16.69)$ & $\mathrm{NA}$ \\
Digit span (WISC) & $96.7(10.2)$ & $95.6(15.3)$ & \\
Forward & & & $6.0(0.9)$ \\
Backward & $5.7(1.2)$ & $5.7(0.9)$ & $4.2(0.9)$ \\
Achenbach (borderline or pathological range) & & \\
Externalization problems & $1 / 10$ & $4.4(0.9)$ & $\mathrm{NA}$ \\
Internalization problems & $3 / 10$ & $4 / 10$ & $\mathrm{NA}$ \\
Depression/Anxiety & $3 / 10$ & $3 / 10$ & $\mathrm{NA}$ \\
\hline
\end{tabular}

a Among the subjects who underwent left TLE, 5 were 11-13 years old and 5 were 13-15 years old. Among the subjects who underwent right TLE, 3 were $11-$ 13 years and 7 were $13-15$ years old. Among control subjects, 20 were $11-13$ years old and 20 were $13-15$ years old.

b Not applicable.

Dysembryoplastic neuroepithelial tumor.

the same for both lists (three learning trials, delayed recall) and the tasks are considered to be matched. Memory for neutral words was performed using word lists taken from Signoret's memory battery $[15,16]$. Memory for emotional words was assessed using a new word list task composed of affective words ( 6 positive words, 6 negative words). This list was drawn from the affective norms of a corpus produced by children and adolescents in an emotional verbal fluency task [21]. Words were chosen from the 25 most generated words in the categories "happy things" (music, laughing, sun, party, friend, holiday) and "sad and scary things" (fire, dark, war, divorce, nightmare, ghost). The number of correct words recalled (per 12) is noted for each recall task.

\subsection{Procedure}

Parents of both children with epilepsy and healthy controls gave informed consent for the study. Participants were tested individually in two sessions lasting $15 \mathrm{~min}$. The order of presentation of emotional and neutral lists was counterbalanced across participants. The first evaluation session began with presentation and immediate recall of the story, and continued with neutral (or emotional) list learning, delayed recall of the story, Digit Span, and delayed neutral (or emotional) list recall. The second session (1-week to 1-month delay for the control group and a few hours for clinical group) comprised emotional (or neutral) list learning, followed by a retention interval during which participants performed nonrelated tasks (coding (WISC-III [22] and verbal fluency task) and delayed recall of an emotional (or neutral) list. Intervals between the immediate and delayed task conditions were approximately $10 \mathrm{~min}$

\section{Results}

\subsection{Preliminary control}

Statistical analyses revealed that for word list learning and delayed recall, there was neither a significant ordering effect (all 
$F(1,54)$ values $<1, \mathrm{~ns}$ ) nor a gender effect (respectively $F(1,54)<1$ and $F(1,54)<1.03$, ns). In addition, when the groups were split into two subsamples according to age (11-13 and 13-15 years), no significant age effect (all $F(1,54)$ values $<1$, ns) was noted. These three factors were thus excluded from later analyses. Similarly, there was no significant age or gender effect on immediate (respectively $F(1,57)=2.58$, ns, and $F(1,57)<1$, ns) and delayed (all $F(1,57)$ values $<1$, ns) story recall. Because of this lack of an effect, patients' performance was compared with that of all healthy subjects, all ages and genders taken together.

\subsection{Global results}

Separate ANOVAs were conducted on global story and list recall scores with group (control vs left TLE) as between-subject factor and material (emotional versus neutral) as within-subject factor. The global story recall score was obtained by summing immediate and delayed performance. Global list score was the sum of scores at the three learning trials and after delay. Healthy subjects performed better than those with LTE in story recall $(t(58)=4.93, P /$ $2<0.005)$, and emotional details were globally better remembered than neutral ones $(t(58)=3.58, P / 2<0.05)$. Nevertheless, when the effect of emotion was studied in each sample separately, emotional enhancement of narrative memory was significant in the control group $(t(39)=3,85, P / 2<0.001)$ but not in the LTE group $(F(1,19)<1, n s)$. For word list recall, group and material interacted significantly $(F(1,58)=5,84, P<0.05)$. Post hoc analysis (NewmanKeuls statistics) revealed that memory for emotional words was better than that for neutral words only in the control group $(P /$ $2<0.025$ ) (Table 2, Fig. 1).

\subsection{Story recall}

Separate two-factor ANOVAs were conducted on immediate and delayed story recall performance, with group (left TLE, right

Table 2

Mean number of units of information recalled in the immediate and delayed conditions: global results.

\begin{tabular}{llllll}
\hline & \multicolumn{2}{l}{ Immediate story recall } & & \multicolumn{2}{l}{ Delayed story recall } \\
\cline { 2 - 3 } \cline { 5 - 6 } \cline { 5 - 6 } & Neutral info & Emotional info & & Neutral info & Emotional info \\
\hline Left TLE & $4.40(1.17)^{\mathrm{a}}$ & $5.50(1.90)$ & & $4.60(0.70)$ & $5.50(1.96)$ \\
Right TLE & $6.90(1.66)$ & $6.90(2.38)$ & & $6.30(1.64)$ & $7.10(2.64)$ \\
Controls & $7.58(1.69)$ & $8.48(1.41)$ & & $7.08(1.79)$ & $8.33(1.47)$ \\
\hline
\end{tabular}

${ }^{a}$ Values are means (SD).

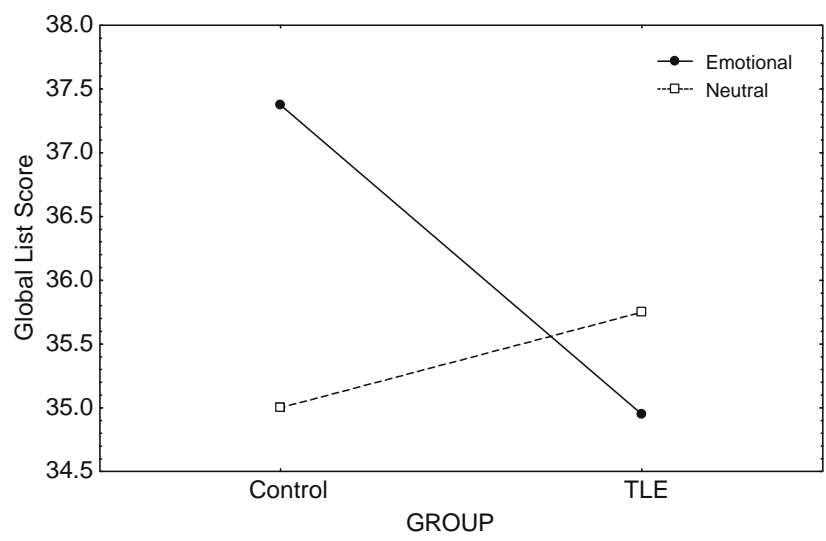

Fig. 1. Global emotional and neutral list recall scores for the left TLE and control groups.
TLE or controls) as a between-subject factor and material (emotional and neutral) as a within-subject factor. An additional three-factor ANOVA was conducted to test memory loss between immediate and delayed story recall, with group as between-subject factor and material and time (immediate and delayed) as within-subject factors. For unilateral comparisons, $F$ statistics were transformed in unilateral $t$ tests.

Controls performed significantly better than patients on both immediate $(t(57)=5.67, P / 2<0.0005)$ and delayed $(t(57)=4.66$, $P / 2<0.0005$ ) story recall (see Table 3 ). Memory deficit in patients with epilepsy was greater in those with left TLE than in those with right TLE for both immediate $(t(57)=3.23, P / 2<0.005)$ and delayed $(t(57)=2.58, P / 2<0.025)$ story recall.

No significant global interaction between group and material was found, so we compared emotion effects within each group for immediate and delayed story recall $(F(2,57)<1$, ns). Memory performance on immediate $(t(57)=3, P / 2>0.005)$ and delayed $(t(57)=4.50, P / 2<0.0005)$ story recall in the control group was characterized by emotional enhancement. A similar nonsignificant tendency was found in the left TLE group for immediate $(F(1,57)=3.37$, ns $)$ and delayed $(F(1,57)=2.62$, ns $)$ story recall and in the right TLE group for delayed story recall only $(F(1,57)=1.79, \mathrm{~ns})$. When global story recall scores are taken into account, there was no significant beneficial effect of emotion on those with left $\operatorname{TLE}(F(1,9)=2.65$, ns $)$ or right $\operatorname{TLE}(F(1,9)<1$, ns $)$.

Memory loss between immediate and delayed story recall was significant in healthy children and adolescents $(t(57)=3.79, P /$ $2<0.0005$ ), but was not modulated by the emotional or neutral nature of the material (see Fig. 2). Significant forgetting could not be concluded in the epilepsy groups (right TLE: $F(1,57)=1.36$, ns; left TLE: $F(1,57)<1$, ns).

\subsection{Recall of word lists}

Separate ANOVAs were conducted on word list performance. For word list learning, first a three-factor ANOVA with group (right TLE, left TLE, controls) as between-subject factor and list (emotional and neutral) and trial (first, second, and third) as within-subject factors was conducted. A second analysis comprised a twofactor ANOVA, again with group as between-subject factor and emotional valence (positive and negative) and trials as within-subject factors. For delayed word list recall, the ANOVAs were the same, with the exception that no trial factor was included. To study memory loss between immediate and delayed word list recall, a supplementary three-factor ANOVA was conducted, with group as between-subject factor and list and time (immediate and delayed recall) as within-subject factors. For unilateral comparisons, $F$ statistics were transformed in unilateral $t$ tests (Table 4).

When learning a new word list or recalling this list after a short delay, healthy children and adolescents demonstrated better memory performance than young patients with epilepsy. However, these results were not statistically significant, whatever the list condition (emotional: $F(1,57)=1.73$, ns; neutral: $F(1,57)<1$, ns). In addition, the patients with LTE and RTE performed similarly in

Table 3

Mean number of units of information recalled in the immediate and delayed conditions: story recall.

\begin{tabular}{llllll}
\hline & \multicolumn{2}{l}{ Immediate story recall } & & \multicolumn{2}{l}{ Delayed story recall } \\
\cline { 2 - 3 } \cline { 5 - 6 } \cline { 5 - 6 } & Neutral info & Emotional info & & Neutral info & Emotional info \\
\hline Left TLE & $4.40(1.17)^{\mathrm{a}}$ & $5.50(1.90)$ & & $4.60(0.70)$ & $5.50(1.96)$ \\
Right TLE & $6.90(1.66)$ & $6.90(2.38)$ & & $6.30(1.64)$ & $7.10(2.64)$ \\
Controls & $7.58(1.69)$ & $8.48(1.41)$ & & $7.08(1.79)$ & $8.33(1.47)$ \\
\hline
\end{tabular}

a Values are means (SD). 


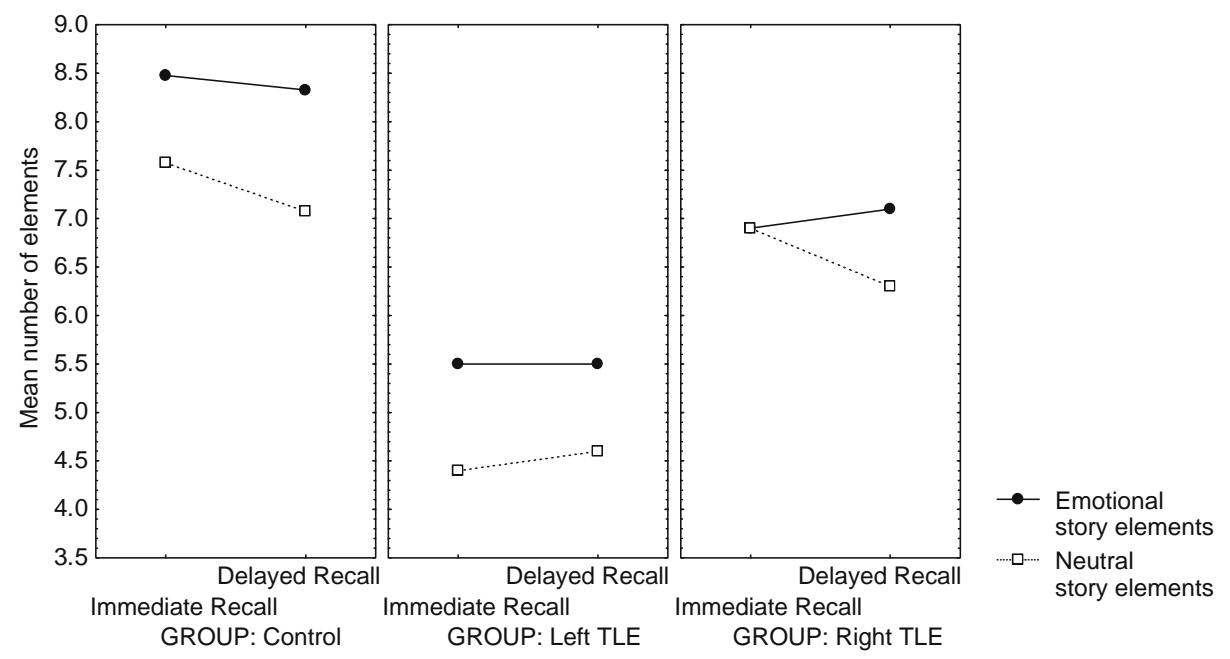

Fig. 2. Memory loss across retention interval for the sum of emotional and neutral items, respectively, for immediate and delayed story recall in the left and right TLE groups.

Table 4

Mean number of words recalled in the immediate and delayed conditions

\begin{tabular}{|c|c|c|c|c|c|c|c|c|}
\hline & \multicolumn{4}{|c|}{ Emotional word list } & \multicolumn{4}{|c|}{ Neutral word list } \\
\hline & Trial 1 & $\begin{array}{l}\text { Trial } \\
2\end{array}$ & $\begin{array}{l}\text { Trial } \\
3\end{array}$ & $\begin{array}{l}\text { Delayed } \\
\text { recall }\end{array}$ & $\begin{array}{l}\text { Trial } \\
1\end{array}$ & $\begin{array}{l}\text { Trial } \\
2\end{array}$ & $\begin{array}{l}\text { Trial } \\
3\end{array}$ & $\begin{array}{l}\text { Delayed } \\
\text { recall }\end{array}$ \\
\hline Left TLE & $\begin{array}{l}6.40 \\
(1.51)^{a}\end{array}$ & $\begin{array}{l}9.40 \\
(1.43)\end{array}$ & $\begin{array}{l}10.30 \\
(1.64)\end{array}$ & $\begin{array}{l}8.30 \\
(2.95)\end{array}$ & $\begin{array}{l}7.20 \\
(1.69)\end{array}$ & $\begin{array}{l}9.30 \\
(1.95)\end{array}$ & $\begin{array}{l}10.30 \\
(1.34)\end{array}$ & $\begin{array}{l}8.80 \\
(2.25)\end{array}$ \\
\hline $\begin{array}{l}\text { Right } \\
\text { TLE }\end{array}$ & $\begin{array}{l}6.70 \\
(2.50)\end{array}$ & $\begin{array}{l}8.90 \\
(1.52)\end{array}$ & $\begin{array}{l}10.10 \\
(1.52)\end{array}$ & $\begin{array}{l}9.80 \\
(1.69)\end{array}$ & $\begin{array}{l}6 \\
(1.25)\end{array}$ & $\begin{array}{l}9.60 \\
(0.97)\end{array}$ & $\begin{array}{l}10.60 \\
(1.43)\end{array}$ & $\begin{array}{l}9.70 \\
(2.11)\end{array}$ \\
\hline Controls & $\begin{array}{l}7.15 \\
(1.55)\end{array}$ & $\begin{array}{l}9.88 \\
(1.45)\end{array}$ & $\begin{array}{l}10.60 \\
(1.06)\end{array}$ & $\begin{array}{l}9.75 \\
(1.69)\end{array}$ & $\begin{array}{l}6.58 \\
(1.36)\end{array}$ & $\begin{array}{l}9.10 \\
(1.35)\end{array}$ & $\begin{array}{l}10.25 \\
(1.51)\end{array}$ & $\begin{array}{l}9.08 \\
(1.95)\end{array}$ \\
\hline
\end{tabular}

${ }^{\text {a }}$ Values are means (SD).

word list learning, in both the emotional $(F(1,57)<1$, ns $)$ and neutral $(F(1,57)<1, \mathrm{~ns})$ conditions. For delayed recall, patients with right TLE tended to show better memory performance than those with left TLE, even though this tendency did not reach statistical significance in the emotional $(F(1,57)=2.58$, ns) or neutral $(F(1,57)<1$, ns $)$ condition.

There was a significant memory gain across the three trials of learning for all subjects $(F(2114)=288.91, P<0.001)$. Post hoc analysis (Tukey's HSD test) indicated that the improvement between trials was significant, compared one by one in each group $(P / 2<0.001)$. As discussed earlier, emotional modulation was studied separately in each group, as no significant global interaction between group and list could be elicited $(F(2,57)=2,54$, ns). A significant emotional memory enhancement effect on word list learning could be described in controls $(t(57)=2.88, P / 2<0.005)$ but not in the epilepsy groups (left TLE and right TLE: $F(1,57)<1$, ns). Indeed, control subjects performed better when learning emotional words than neutral words (see Fig. 3). As shown in Fig. 4, this beneficial emotional effect on memory was still strong for delayed word list recall in the control group $(t(57)=2.40, P / 2<0.025)$, but was not observed in the clinical groups (left TLE and right TLE: $F(1,57)<1$, ns). Analyses of global list recall scores confirmed that memory for words was not improved by emotion in patients with left or right TLE (both $F(1,9)$ values $<1$, ns).

With respect to the memory loss between immediate and delayed list recall, forgetting reached significance in the control and left TLE groups (respectively $t(57)=5.33, \quad P / 2<0.0005$ and $t(57)=4.6, P / 2<0.0005)$, but not in the right TLE group $(F(1,57)=2.49$, ns) (see Fig. 4). Memory loss was not influenced by emotional or neutral condition $(F(1,57)<1$, ns $)$.
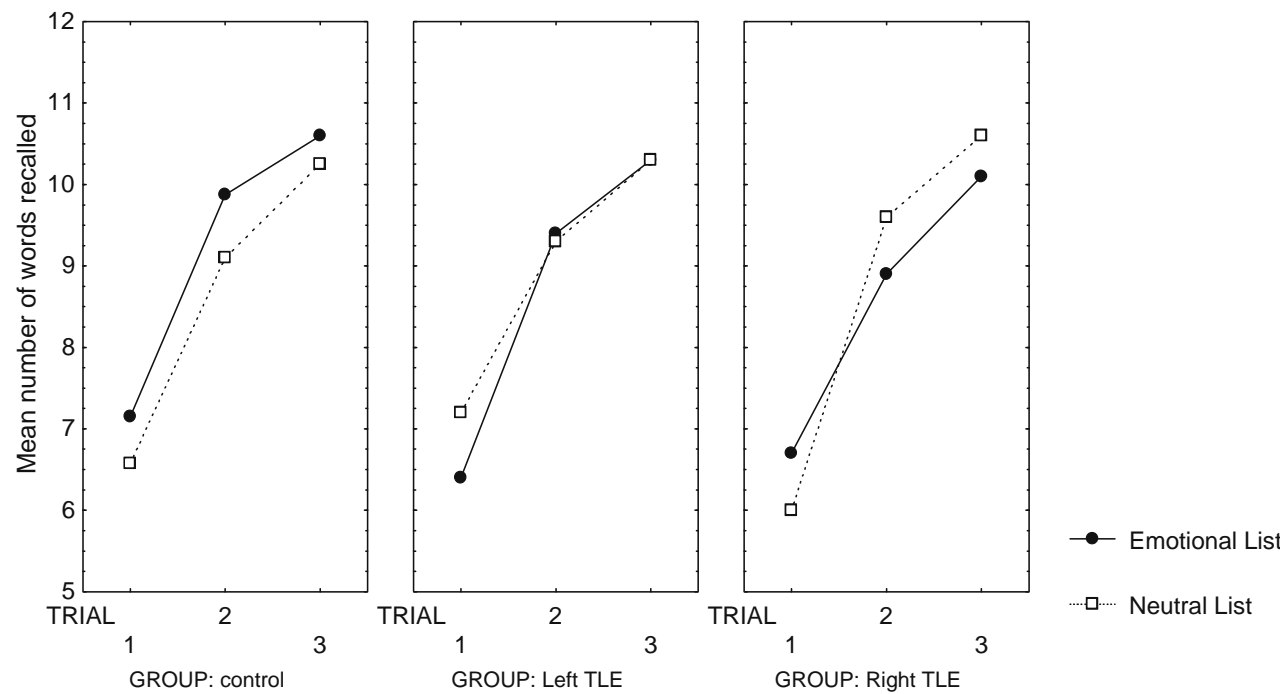

Fig. 3. Learning effects across the three trials in the left and right TLE groups. 

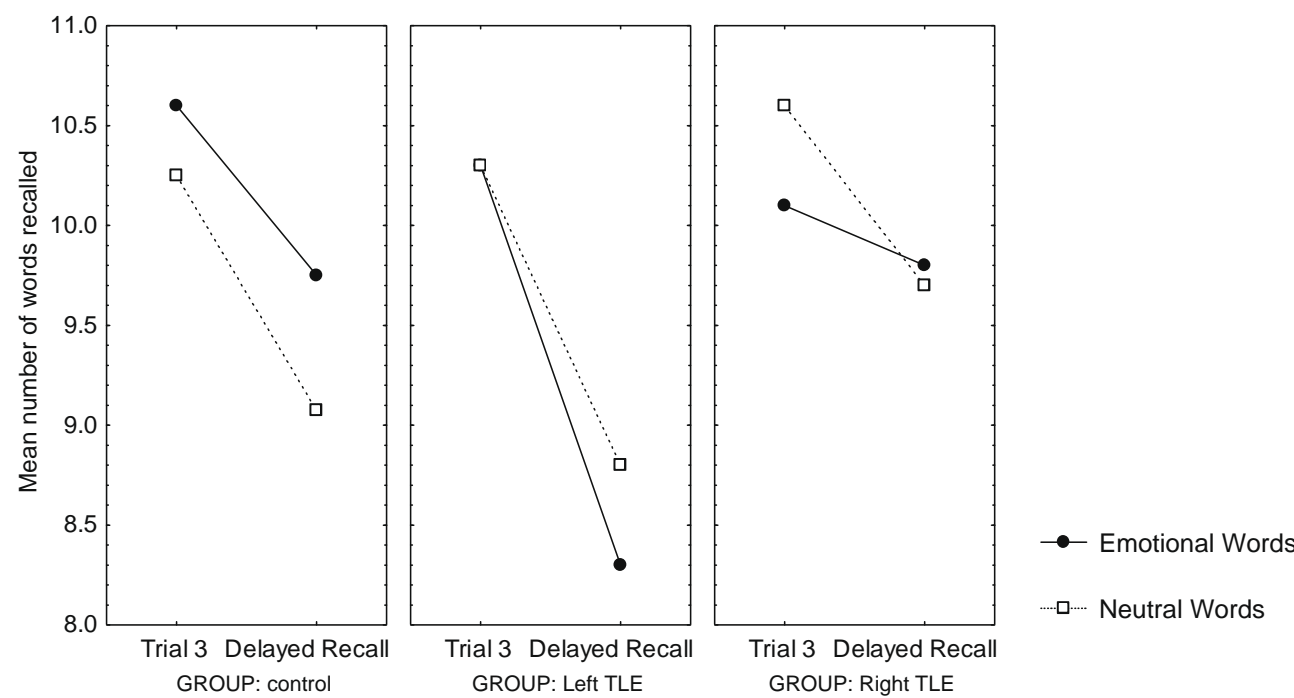

Fig. 4. Memory loss across retention interval for emotional and neutral words in each group.

Table 5

Mean number of words recalled as a function of emotional valence for immediate and delayed recall.

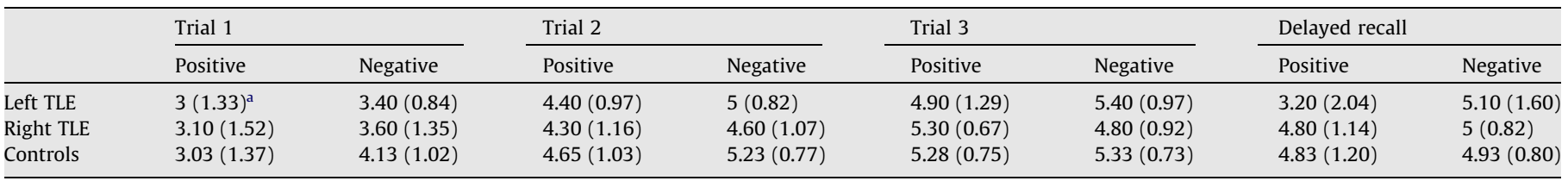

a Values are means (SD).

The emotional valence effect was significant for healthy subjects during verbal learning $(t(57)=4.29, P / 2>0.0005)$ and for subjects with left TLE during delayed word list recall $(t(57)=4.49, P$ / $2<0.0005$ ). In these two cases, the valence effect resulted in better recall of negative words than of positive words (see Table 5).

\subsection{Memory performance and behavioral data}

In the left and right TLE groups, there was no effect of anxiety/ depression on global story and list recall (respectively $F(1,16)=4.32$ and $F(1,16)<1$, ns), when patients were assigned to pathological or normal subsamples according to their CBCL score. Furthermore, $\mathrm{CBCL}$ condition did not interact with emotion or epileptic lateralization (all $F(1,16)$ values $<1$, ns).

\section{Discussion}

The research described here represents the first study aimed at comparing emotional impact on memory in children and adolescents with TLE and a healthy control population. Our results highlight the existence of emotional memory enhancement in late childhood and adolescence. Nevertheless, no beneficial effect of emotion on memory was found in the subjects in our clinical group, who exhibit early temporal lobe dysfunction.

Few studies have been conducted with the aim of studying emotional memories in children. Most of these studies have focused on narrative or autobiographical memory during childhood (e.g., $[23,24])$ and did not permit direct comparison of children's abilities to recall emotional and nonemotional information. More recently, Davidson et al. [25] studied emotional enhancement systematically by asking children to recall emotional and nonemotional information from stories reflecting everyday life. They showed that 7- to 11-year-old children recalled more emotional information than neutral information. The present study indicates that encoding and retrieval are significantly modulated by emotion in healthy children in both story recall and word list tasks. Immediate recall is indeed better for emotional words, so that encoding seems facilitated by emotional content. It can be assumed that emotion brings additional indications to memorize verbal stimuli [25]. Emotional memory traces thus become richer than neutral memory representations, and emotional word delayed recall is more efficient than neutral word retrieval, as has been shown in adults $[1,2]$. The third memory process-consolidation-does not seem to benefit from emotional enhancement but we used only a very short delay.

In the subjects with TLE, memory performances differed according to the task: a memory deficit was demonstrated in story recall, whereas verbal learning was preserved. Furthermore, on story recall, children and adolescents with left TLE performed worse than those with right TLE. This suggests a material-specific effect reflecting hemispheric specialization, as has already been demonstrated in children with epilepsy (pre- and postsurgery) using the same story task without taking account of the affective value of information [14,15]. On the other hand, the control and clinical groups achieved similar global memory scores in word list learning and delayed list recall. Several studies have previously reported that children with TLE can perform relatively well in word list recall $[26,27]$.

With respect to the emotional impact on memory, there were qualitative differences between the control and clinical samples, as the children and adolescents with TLE did not seem to benefit from emotional enhancement of memories. It was even more evident that only healthy subjects demonstrated increased memory for emotional words in the list recall task. A similar pattern has been shown on story recall in adults with left TLE, suggesting that an intact amygdala-hippocampus complex is essential for the 
modulation of memory by emotion [11]. Furthermore, there was a significant memory deficit in delayed recall in our subjects with left TLE, which points to poor consolidation of verbal memories, as has already been reported in adults with TLE [28]. The lack of emotional enhancement of memory depicted in list learning is central to the debate over emotion-memory relationships in TLE. Some authors have demonstrated a residual emotional memory enhancement in adults who have undergone unilateral temporal resection $[8,29]$. However, the present study is congruent with Adolphs et al. [30] and Buchanan et al. [10], who did not report any emotional memory enhancement in their patients with epilepsy. It can thus be supposed that mesial temporal lobe damage, especially amygdala and hippocampus lesions occurring in early life, can impair emotional memory facilitation. This assumption is supported by Shaw et al. [13], who did not observe emotional memory enhancement in patients with early amygdala lesions suspected to be dysembryoplastic neuroepithelial tumors (DNTs), whereas patients with later damage showed a pattern typical of memory facilitation for emotional material. Our population comprised patients with early temporal lobe damage including a number of patients with DNTs, but our small sample did not allow us to take into account lesion type or seizure frequency. In the future, it will be interesting to conduct comparisons between pre- and postsurgical emotional verbal memory because children who have undergone temporal lobe surgery have better memory outcome than adults, suggesting that compensatory cognitive processes may occur after anterior-temporal resection in young patients [15,26,27].

Finally, word list learning provides some additional clues to emotional valence effects. Strikingly, healthy subjects recalled more negative than positive words during verbal learning, and the subjects with left TLE better recalled negative words during delayed word list recall. This suggests a negativity bias in our young population [31]. The "adolescence crisis period" may produce mood modifications as well as a decrease in self-esteem and vulnerability [32]. This affective state may interfere with memory; a negativity bias has been reported in depressed adolescents on an emotional story recall task [33] and an adjective recall task [34]. Similarly, children and adolescents with major depressive disorder demonstrate deficits in memory for fearful faces, but not angry or happy faces [35]. In our study, six patients with TLE had pathological or borderline scores on the Anxiety/Depression scale of the CBCL, but their memory performances for emotional words did not seem to be affected by this condition. Unfortunately, however, behavioral measures such as the Anxiety/Depression scale were not used in our control sample. To link the degree of negativity bias with the presence of depression or anxiety elements, further experiments with a depression scale or anxiety measure in both clinical and healthy groups are needed [36,37]. The negativity bias we observed did not last on delay, except in the left TLE group, especially for positive words. Such a result may be related to the different contributions of the left and right mesial temporal regions to both memory and emotion processing $[10,38,39]$.

In conclusion, the present study suggests a negative impact of temporal lobe epilepsy on the development of emotional memory. Our findings clearly demonstrate emotional verbal memory enhancement in healthy children and adolescents, but evoke a lack of emotional memory modulation in young patients with TLE. This first study encourages future research in this field to understand the atypical pattern of development of emotional memory in children with TLE, taking into account the influence of several medical (age at onset, seizure frequency, pre-/postsurgery) and behavioral variables, as well as the nature (verbal-nonverbal) of the material to be learned and remembered.

\section{Acknowledgments}

We thank all the children and their families who participated in this study. We thank Nathalie Golouboff for her participation in assessing the children with epilepsy. This work was supported by a grant from the French Foundation for the Research on Epilepsy (FFRE) to Isabelle Jambaqué.

\section{References}

[1] Ferré P. Effects of level of processing on memory for affectively valenced words. Cogn Emot 2003;17:859-80.

[2] Kensinger EA, Corkin S. Memory enhancement for emotional words: are emotional words more vividly remembered than neutral words? Mem Cogn 2003;31:1169-80.

[3] Nagae S, Moscovitch M. Cerebral hemispheric differences in memory of emotional and nonemotional words in normal individuals. Neuropsychologia 2002; $40: 1601-7$

[4] Brierley B, Medford N, Shaw P, David AS. Emotional memory for words: separating content and context. Cogn Emot 2007;21:495-521.

[5] Otani H, Libkuman TM, Widner RLJ, Graves EI. Memory for emotionally arousing stimuli: a comparison of younger and older adults. J Gen Psycho 2007:134:23-42.

[6] Dolan RJ. Emotion, cognition, and behavior. Science 2002;298:1191-4.

[7] Helmstaedter C, Sonntag-Dillender M, Hoppe C, Elger CE. Depressed mood and memory impairment in temporal lobe epilepsy as a function of focus lateralization and localization. Epilepsy Behav 2004;5:696-701.

[8] Phelps EA, LaBar KS, Spencer DD. Memory for emotional words following unilateral temporal lobectomy. Brain Cogn 1997;35:85-109.

[9] Brierley B, Medford N, Shaw P. Emotional memory and perception in temporal lobectomy patients with amygdala damage. J Clin Exp Neuropsychol 2004;75:593-9.

[10] Buchanan TW, Denburg NL, Tranel D, Adolphs R. Verbal and nonverbal emotional memory following unilateral amygdala damage. Learn Mem 2001;8:326-35

[11] Frank JE, Tomaz C. Lateralized impairment of the emotional enhancement of verbal memory in patients with amygdala-hippocampus lesion. Brain Cogn 2003;52:223-30.

[12] Richardson MP, Strange BA, Dolan RJ. Encoding of emotional memories depends on amygdala and hippocampus and their interactions. Nat Neurosci 2004;7:278-85.

[13] Shaw P, Brierley B, David AS. A critical period for the impact of amygdala damage on the emotional enhancement of memory? Neurology 2005;65:326-8.

[14] Jambaqué I, Dellatolas G, Dulac O, Ponsot G, Signoret J. Verbal and visual memory impairment in children with epilepsy. Neuropsychologia 1993;31:1321-37.

[15] Jambaqué I, Dellatolas G, Fohlen M, et al. Memory functions following surgery for temporal lobe epilepsy in children. Neuropsychologia 2007;45:2850-62.

[16] Nolan MA, Redoblado MA, Lah S, et al. Memory function in childhood epilepsy syndromes. J Paediatr Child Health 2004:40:20-7.

[17] Gleissner U, Sassen R, Lendt M, Clusmann H, Elger CE, Helmstaedter C. Pre- and postoperative verbal memory in pediatric patients with temporal lobe epilepsy. Epilepsy Res 2002;51:287-96.

[18] Golouboff N, Fiori N, Delalande O, Fohlen M, Dellatolas G, Jambaqué I. Impaired facial expression recognition in children with temporal lobe epilepsy: impact of early seizure onset on fear recognition. Neuropsychologia 2008;46:1415-28.

[19] Gleissner U, Fritz NE, Von Lehe M, Sassen R, Elger CE, Helmstaedter C. The validity of the Child Behavior Checklist for children with epilepsy. Epilepsy Behav 2008;12:276-80.

[20] Signoret J. Batterie d'efficience mnésique-BEM 144. Paris: Elsevier; 1991.

[21] Doost HTN, Moradi AR, Taghavi MR, Yule W, Dalgleish T. The development of a corpus of emotional words produced by children and adolescents. Pers Indiv Diff 1999;27:433-51.

[22] Wechsler D. Echelle d'intelligence de Wechsler pour enfants: WISC. Paris: Edition du Centre de Psychologie Appliquée; 1991.

[23] Fivush R. Emotional content of parent-child conversations about the past. In: Nelson CA, Nelson CA, editors. Memory and affect in development. Hillsdale, NJ: Lawrence Erlbaum Associates; 1993. p. 39-77.

[24] Liwag MD, Stein NL. Children's memory for emotional events: the importance of emotion-related retrieval cues. J Exp Child Psychol 1995;60:2-31.

[25] Davidson D, Luo Z, Burden MJ. Children's recall of emotional behaviours, emotional labels, and nonemotional behaviours: does emotion enhance memory? Cogn Emot 2001;15(1):1-26.

[26] Gleissner U, Sassen R, Schramm J, Elger CE, Helmstaedter C. Greater functional recovery after temporal lobe epilepsy surgery in children. Brain 2005;128:2822-9.

[27] Mabbott DJ, Smith ML. Memory in children with temporal or extra-temporal excisions. Neuropsychologia 2003;41:995-1007.

[28] Äikiä M, Salmenperä T, Partanen K, Kälviäinen R. Verbal memory in newly diagnosed patients and patients with chronic left temporal lobe epilepsy. Epilepsy Behav 2001;2:20-7. 
[29] Brierley B, Medford N, Shaw P, David AS. Emotional memory and perception in temporal lobectomy patients with amygdala damage. J Neurol Neurosurg Psychiatry 2004;75:593-9.

[30] Adolphs R, Tranel D, Denburg N. Impaired emotional declarative memory following unilateral amygdala damage. Learn Mem 2000;7:180-6.

[31] Leigland LA, Schulz LE, Janowsky JS. Age related changes in emotional memory. Neurobiol Aging 2004;25:1117-24.

[32] Galambos NL, Costigan CL. Emotional and personality development in adolescence. In: Lerner RM, Easterbrooks MA, Mistry J, Lerner RM Easterbrooks MA, Mistry J, editors. Handbook of psychology: developmental psychology, vol. 6. Hoboken, NJ: Wiley; 2003. p. 351-72.

[33] Bishop SJ, Dalgleish T, Yule W. Memory for emotional stories in high and low depressed children. Memory 2004;12:214-30.

[34] Neshat-Doost HT, Taghavi MR, Moradi AR, Yule W, Dalgleish T. Memory for emotional trait adjectives in clinically depressed youth. J Abnorm Psycho 1998;107:642-50.
[35] Pine DS, Lissek S, Klein RG, et al. Face-memory and emotion: associations with major depression in children and adolescents. J Child Psychol Psychiatry 2004;45:1199-208.

[36] Birleson P. The validity of depressive disorder in childhood and the development of a self-rating scale: a research report. J Child Psychol Psychiatry 1981;22:73-88.

[37] Spence SH. Structure of anxiety symptoms among children: a confirmatory factor-analytic study. J Abnorm Psychol 1997;106:280-97.

[38] Glogau S, Ellgring H, Elger CE, Helmstaedter C. Face and facial expression memory in temporal lobe epilepsy patients: preliminary results. Epilepsy Behav 2004;5:106-12.

[39] Batut AC, Gounot D, Namer IJ, Hirsch E, Kehrli P, Metz-Lutz MN. Neural responses associated with positive and negative emotion processing in patients with left versus right temporal lobe epilepsy. Epilepsy Behav 2006;9:415-23. 